\title{
Assessing Urban Households' Willingness to Pay for Standalone Solar Photovoltaic Systems: A Case Study of Lagos, Nigeria
}

\author{
Anthony I. Ugulu *1, Clinton Aigbavboa ${ }^{2}$ \\ ${ }^{1}$ Department of Construction Management and Quantity Surveying, University of Johannesburg, \\ Auckland Park, Johannesburg, South Africa \\ e-mail: anthonyugulu@yahoo.com \\ ${ }^{2}$ Department of Construction Management and Quantity Surveying, University of Johannesburg, \\ Auckland Park, Johannesburg, South Africa \\ e-mail: caigbavboa@.uj.ac.za
}

Cite as: Ugulu, A. I., Aigbavboa, C., Assessing Urban Households' Willingness to Pay for Standalone Solar Photovoltaic Systems: A Case Study of Lagos, Nigeria, J. sustain. dev. energy water environ. syst., 7(3), pp 553-566, 2019, DOI: https://doi.org/10.13044/j.sdewes.d7.0274

\begin{abstract}
Citizen participation would be crucial towards transforming the global electricity infrastructure. Household involvement would be particularly vital for nations with underdeveloped grid and widespread electricity outages like Nigeria. This study investigates urban households' willingness to pay and participate in off-grid solar photovoltaic adoption in Lagos, Nigeria. Results reveal that households have an above average interest in photovoltaic generated electricity. This was the case irrespective of tenancy type. Age, income and education also influenced participation. Although overall willingness to pay was positive, it was higher in the presence of government support. The preferred rate of fiscal incentive support was between 50-60\%. In addition, when made available and given the opportunity, many households would participate in the feed-in-tariff export scheme. The implications of the study are detailed and suggestions for increased participation presented. Findings point to the importance of regulatory reforms and political intervention using favourable monetary and non-fiscal support incentives.
\end{abstract}

\section{KEYWORDS}

Electricity supply, Solar photovoltaic systems, Willingness to pay, Contingent valuation, Households, Urban Nigeria.

\section{INTRODUCTION}

With inhabitants of over 180 million people, Nigeria represents about $47 \%$ of the population of West Africa [1]. The African continent has the highest number of people with the least access to electricity and energy supplies [2] and therefore has one of the least per capita electricity consumption in sub-Saharan Africa [3]. At $6 \mathrm{GW}$, the central grid electricity infrastructure in Nigeria is unable to meet demand even for the $40 \%$ grid connected urban households [4]. This low electricity access and the unstable supply from the grid electricity infrastructure has slowed down growth and socio-economic development.

\footnotetext{
${ }^{*}$ Corresponding author
} 
As nations transition to low-carbon energy technologies, new opportunities are presented for Nigeria to transform the energy sector and economy using renewables. The motivation for the global shift in energy policy towards climate action is triggered by the desire for energy security and a reduction in carbon emissions [5]. The use of combustible fuels for power production and energy use in the built environment is a key cause of carbon dioxide $\left(\mathrm{CO}_{2}\right)$ emissions. A UN report estimates that globally $66 \%$ of aggregate electricity production comes from fossil fuels contributing to approximately $60 \%$ of Greenhouse Gas (GHG) emissions responsible for climate change [6].

As the prices of crude petroleum products from which Nigeria generates over $75 \%$ of its revenue [7] have stagnated, the Nigerian government is desperate to diversify its energy portfolio and improve electricity supply to consumers. The government intends to include green energy technologies such as solar in the energy mix with solar Photovoltaic (PV) electricity targeted to contribute $13 \mathrm{GW}$ by 2030 [7]. Also, as a signatory to the Paris agreement adopted in December 2015 [8], Nigeria has started to make changes to its energy policy to include climate action plans with a number of electricity sector reforms for short, medium and long terms [7].

These considerations are not being made by the Nigerian government alone. Households and electricity end-users who have for decades substituted grid electricity with private power generators which run on petrol and diesel have begun to seek alternative and more reliable power. For years, half of all electricity generated in Nigeria was produced privately [9]. However, following the removal of fuel subsidies, the prices of petroleum products by which the generators are operated have increased significantly. Similarly, electricity tariffs rose by almost $90 \%$ [10] making it less attractive compared to cleaner sources.

Many studies have been carried out on the electricity sector challenges in Nigeria and the importance of including modern renewables in the energy mix [4]. While some focus on rural electrification [11], others concentrate mostly on centrally generated and supplied electricity using renewables. This is because of the view that the longstanding power sector challenge is a supply-oriented one thereby treating the solution as such [12]. This approach has yielded little results over the past 30 years [13].

The study by Adhekpukoli [14] on the democratization of electricity in Nigeria considers the vital role electricity end-users can play but without practical demonstration of how this would work. No known study has assessed household willingness to participate in green electricity programmes in Nigeria despite a high rate of own power generation. This could be due to the false assumption that the citizens cannot afford innovative power technologies like PV. This present study seeks to fill this essential knowledge gap by investigating household willingness to participate in own power generation using off-grid PV.

Contributing to the Sustainable Development Goals (SDG) 7 to make clean energy affordable, SDG 9 on innovation and infrastructure and SDG 12 which encourages responsible consumption and production, this study specifically assesses the Willingness To Pay (WTP) for standalone solar PV using urban Lagos households as case study. The paper is structured as follows. The next section explores consumer responses and WTP for green energy literatures. This is followed by the materials and methods applied to the study. Subsequently, the results and analysis of findings are presented. Lastly, the discussion and conclusions section finalise the paper with recommendations for increased participation.

\section{A REVIEW OF CONSUMER RESPONSES AND WILLINGNESS TO PAY FOR GREEN POWER AND MICROGENERATION TECHNOLOGIES}

Studies abound on consumer responses and WTP for renewable energy and green electricity. Oliver et al. [15] carried out their study in Cape Peninsula, South Africa. They reported a high WTP for green electricity from higher income earners. Using Greek 
households, Sardianou and Genoudi, reported the role of income towards WTP for renewable energy sources. Middle-aged, highly educated people were found to display a greater WTP [16]. For Hast et al. [17], the case study was Shanghai, China. They recorded cost savings and energy security as drivers while capital costs and product quality issues were a barrier to participation. With the exception of the study by Oliver et al. [15], the above studies are predominantly focused on advanced economies but research is beginning to emerge in developing countries in Africa [18].

Many of the available studies concentrate on household preferences in the estimation of WTP for green electricity $[19,20]$. There are generally two kinds of WTP studies. The first category makes use of absolute amounts of the renewable electricity source or percentage premiums to estimate the WTP for non-specific green electricity [17]. The second category tends to apply Contingent Valuation Methods (CVM) or choice experiment as the elicitation method for estimating consumer WTP based on different shares of green electricity, environmental impacts and related metrics [21]. In both categories, the electricity markets are fully liberalised or deregulated to allow consumers the opportunity to choose supplier.

In most studies, WTP is often expressed in either absolute or relative terms as an increase in the total electricity bill payable or an increase in the price per/kWh or per month of electricity received [22]. Overall, there are differences in the results reported because these studies are carried out in different countries and regions making it circumstantial [23]. It is also due to the different survey methods applied and whether or not the WTP is for green electricity or stand-alone systems such as PV. For instance, in Japan, Nomura and Akai [24] found a WTP for green electricity at 17 USD/month while in Slovenia, Zorić and Hrovatin [22] revealed an average monthly WTP of EUR 4 or 9\% of the monthly electricity bill. More recently, a WTP that is 3 times higher than the monthly electricity bill was reported in South Korea [25] and China [21].

While the generating costs of green electricity and WTP varies by source [19], there have been reported preference for solar over other energy sources like wind [24]. However, fewer studies have investigated the WTP for Microgeneration Technologies (MGTs) such as decentralised solar PV [26]. MGTs refer to the generation of heat or power using a renewable energy source from a system size of $=/<50 \mathrm{~kW}_{\mathrm{p}}$ [27]. This may be due to the high investment cost of a sizeable PV module. However, there is evidence that PV module costs has been consistently falling making it now more affordable compared to decades ago when it was $5 \mathrm{USD} / \mathrm{kWh}$ [3]. Reports indicate it is presently less than $1 \mathrm{USD} / \mathrm{kWh}[3]$. Cost is one of the primary determinants of consumer responses and WTP for green electricity or MGTs [27]. Hence, some studies find that a higher WTP is related to voluntary participation than for mandatory programmes [28]. This finding would be more contextual, region-specific and based on whether or not the location has a stable electricity grid.

Furthermore, the influence of socio-demographic factors on consumer WTP is well documented. Income has been found to be a significant socioeconomic construct in the WTP decisions [15]. Education has also been found to be positively related to WTP for green electricity [16]. Likewise, environmental attitudes and altruism were reported to be motivators in consumer WTP for green electricity [26]. The influence of age and gender while linked to WTP has been mixed [22]. In the estimation of WTP for green electricity, studies apply a variety of CVM and choice experiment models including binary logit [16] and general regression models [23].

\section{MATERIALS AND METHODS}

This section presents some background information of the study location, the rationale for the choice of location, sampling methods and other data gathering approaches followed. 


\section{Study location and rationale}

The household data used for this study was drawn from urban areas in Lagos, Nigeria. An urban area is referred to as a human settlement with a population of between 2,000 to 5,000 and a population density of between 150 to 400 persons $/ \mathrm{km}^{2}$ [29]. At over 20 million, the city has one of the largest populations of any state in Nigeria. It was the former federal capital with leading infrastructural developments. It is the industrial and commercial centre of Nigeria with about $60 \%$ of total industrial investments and foreign trade taking place in this coastal city. It also has the largest ports in Nigeria facilitating imports and exports of goods and services.

As a central location, this metropolitan city is responsible for about $35 \%$ of national GDP. There is also increasing interest in green energy development in the city too [30]. One of the earliest studies that considered large-scale PV utilisation in urban centres focused on Lagos [31] and the above-mentioned points about the city was part of their rationale. Other more important factors for choosing Lagos as a study location include:

- Ideal solar radiation intensity of between 3.54 to $5.43 \mathrm{kWh} / \mathrm{m}^{2}$ day [4];

- High urban population and domestic energy users;

- Diverse mix of people encompassing the affluent, middleclass and poor;

- Good portfolio of dwelling types (especially those suited to roof-top PV).

Colenbrander et al. [32] found that promoting PV and other low carbon energy technologies in cities is proactive and will save expenditure on consumer utility bills, governments' subsidies and save costs of investments in energy infrastructure. Metropolitan households have also been proven to be the most willing to pay for Renewable Energy Technologies (RETs) than rural residents [33].

\section{Multistage cluster sampling}

Using multistage cluster sampling, data was used collected. This sampling method commonly used in geographically dispersed locations like Lagos allow for the division and sub-division of a city into districts or clusters from which smaller areas can be obtained. De Vaus [34] suggests maximising the size of the initial clusters and later selecting fewer households or units. Multi-stage sampling is not uncommon in green power promotion and WTP studies [21] and is effective where there are many municipalities that present logistical challenge [35]. More recently, researchers Arega and Tardesse, applied multistage cluster sampling in their research on WTP for green electricity in urban Ethiopia [18].

Information collected from the Lagos State House of Assembly (LSHA) library and the Nigerian Meteorological Agency (NIMET) led to the effective use of multi-stage cluster sampling. The LSHA directories were used to organise the Local Government Areas (LGA) and municipalities. This approach resulted to a breakdown of Lagos State into 5 major districts known as IBILE which is an acronym for Ikeja, Badagry, Ikorodu, Lagos Island and Epe [30]. Through this approach, all the 20 LGAs and most of the 37 Local Council Development Areas (LCDAs) were covered in the survey. Figure 1 is the map of Lagos highlighting the location of the surveyed households.

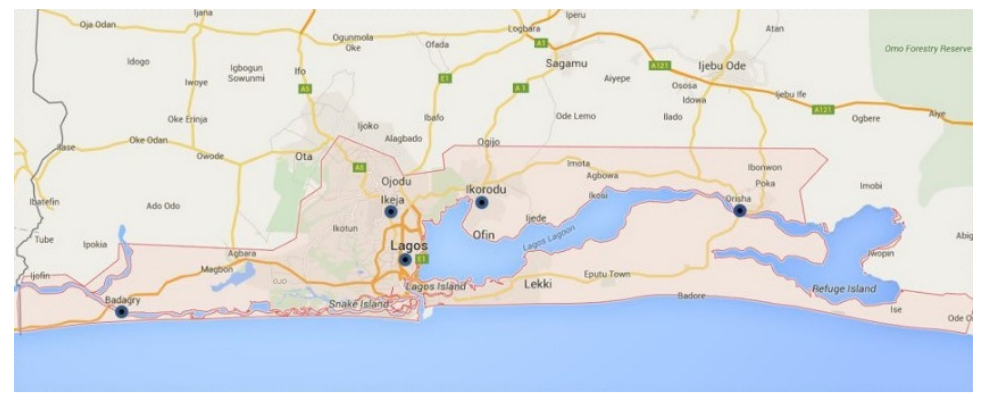

Figure 1. Map of Lagos showing location of surveyed households using IBILE zoning structure 
Ikeja is the largest and comprises of 8 LGAs including Ikeja, Oshodi-Isolo, Mushin and Shomolu LCAs, Badagry comprises of 4 LGAs including Anthony Village which is under Amuwo Odofin LCA and Badagry village, Ikorodu has 1 LGA known as Ikorodu and is the smallest of the LGAs, Lagos comprises of 5 LGAs including Lagos Island, Apapa, Lagos Mainland, Eti-Osa and Surulere, Epe has only 2 LGAs- Epe and Ibeju-Lekki. It is also a generally more affluent area than Ikeja, Badagry and Ikorodu.

\section{Survey design and data collection}

Through household survey, data were collected in Lagos, Nigeria. The data collection mode was a mixture of hand-delivery and emails. A total of 245 questionnaires were administered through the help of 10 properly trained field assistants following pilot testing. 205 questionnaires were delivered by hand and 40 sent by email. In addition to sociodemographic questions, respondents were asked to answer questions covering their awareness and knowledge of solar PV, perception, WTP for standalone PV and likelihood of participating in grid interconnectivity when made available. Respondents were also asked to rate their satisfaction levels with the existing grid distributed electricity. Of the total administered questionnaires, 200 usable responses were returned and 3 via email.

As part of the semi-structured and open-ended questionnaire design, a description of a $5 \mathrm{~kW}_{\mathrm{p}}$ PV that could help meet most of the household energy demand was given. Details of how this module size was determined would be given subsequently. This description also gave the costs of this PV module based on the quotes obtained from installers. Most of the questions were rating and Likert scale types for ease in completion. However, some questions required of respondents to write freely with the 'other, please state' option. It is important to note that in consumer response studies carried out in fully liberalised markets of mostly developed countries, participation in green electricity programmes is assessed based on the amount households are willing to pay for electricity/kWh/month.

In most cases, the households are offered differing green electricity sources such as hydropower, biomass, solar and wind with varying tariff rates [16, 20, 28]. Because this study is in a country with immature electricity grid network and less liberalised electricity markets similar offerings could not be made. It was therefore necessary to ascertain the energy usage of the households in order to identify the suitable PV module size that would help meet the households' energy demand. For this purpose, an energy audit for a typical home in Nigeria was drawn up (Table 1 details). Using this power audit, a $5 \mathrm{~kW}_{\mathrm{p}}$ PV module was deemed ideal with 5 quotes obtained from installers to help determine prices.

Table 1. Household power audit showing appliance ratings and hours of use

\begin{tabular}{cccccc}
\hline Appliance & Unit & Power/Unit [W] & Power [W] & Hours in operation & Daily energy requirement [Wh] \\
\hline Refrigerator & 1 & 500 & 500 & 12 & 6,000 \\
Freezer & 0 & 500 & 0 & 24 & 0 \\
Flat screen TV & 1 & 1,000 & 1,000 & 8 & 8,000 \\
CD/DVD player & 1 & 30 & 30 & 8 & 240 \\
Air conditioner & 0 & 1,100 & 0 & 12 & 0 \\
Ceiling fan & 2 & 80 & 160 & 9 & 1,440 \\
Standing fan & 1 & 80 & 80 & 9 & 720 \\
Computers & 2 & 240 & 480 & 8 & 3,840 \\
Light bulbs & 5 & 60 & 300 & 8 & 2,400 \\
Pressing iron & 1 & 1,000 & 1,000 & 1 & 1,000 \\
Microwave oven & 1 & 750 & 750 & 1 & 750 \\
Blender & 1 & 300 & 300 & 1 & 300 \\
Washing machine & 1 & 400 & 3 & 1,200 \\
Water pump & 0 & 1,200 & 00 & 1 & 0 \\
\hline \\
From the RETScreen data, solar PV annual output computation: \\
Available energy in a day $=7,843.39 \mathrm{kWh} / 365$ days $=>21.49 \mathrm{kWh}$ \\
Percentage daily availability $=21.49 \mathrm{kWh} / 25.89 \mathrm{kWh} \times 100=>83 \%$ & & 25,890 \\
\end{tabular}


The above power audit was essentially conducted to ascertain the size of a solar PV system that would be suitable for the purpose of costing and ensuring adequate supply. For this purpose, solar radiation data was obtained for Lagos using the RETScreen software. This helped to determine the annual output from a $5 \mathrm{~kW}_{\mathrm{p}} \mathrm{PV}$ module which was considered ideal following the energy audit. Often studies indicate system capacity of $3 \mathrm{~kW}_{\mathrm{p}}$ as suitable especially where heating requirements are excluded from the PV device. From the energy audit shown above, it becomes clear that a $5 \mathrm{~kW}_{\mathrm{p}}$ system will meet at least $83 \%$ of the average household's demand. However, this will depend on the number, ratings and combination of appliances used in the dwelling.

In fact, the hypothesised and proposed $5 \mathrm{~kW}_{\mathrm{p}}$ system would meet average power demand comfortably leaving a good margin to accommodate the high starting power of refrigerators. Also, as can be observed, electric cooker was excluded from the above audit because as would be expected, given the power supply challenges, most urban households use gas cookers. This is only reasonable because electricity is highly unstable and power outages frequent. In rural areas, kerosene stoves and wood fuel are mostly used. Note also that some listed appliances have substitutes, e.g. ceiling fan and standing fan can be used in place of air conditioners and vice versa. Furthermore, many listed appliances are non-continuous loads which means that other smaller electronic devices such as mobile phones, tablets and radio can be easily accommodated. Also, if more energy-efficient appliances are used, the entire household demand would be met by the proposed system.

\section{Stated preference against revealed preference}

Consumer choice studies applying WTP can be done using either Stated Preference (SP) or Revealed Preference (RP) methods of elicitation [36]. This paper adopted SP due to the lack of research and market information and because SP is designed to be used when data is extracted from surveys. RP finds application where an observation of the surveyed household's choice decisions is made from a set of alternatives in real markets [37]. Since solar PV is a relatively 'new' technology, it made sense to use SP due to lack of revealed preference data in studies in Africa [38]. SP has been widely used in similar studies [33]. Also, Claudy et al. [39] applied SP in their study of Irish citizens' WTP for microgeneration technologies.

\section{Elicitation methods}

Contingent Valuation Method (CVM) was used because the goal of the survey questionnaire was to identify the barriers and evaluate the value to households of PV. Another common elicitation method is Conjoint Analysis (CA) [36]. CA is useful where the attributes of a product or technology is being assessed as a way of measuring acceptance. Single Bound Dichotomous Choice (SBDC) CVM was used by asking questions that required the respondents to simply answer 'Yes' or 'No' to whether or not they would be willing to pay for PV, 'Yes' or 'No' to whether or not they would prefer fiscal incentives before participation and the possibility of exporting excess generated electricity to the grid if the opportunity arises.

Under the conventional CVM studies, a bidding process is followed. The respondents are offered prices for PV or another Renewable Energy Source Electricity (RES-E). In the initial round, the respondents will have to choose 'Yes' or 'No' from listed PV prices or percentage of carbon reduction etcetera. Respondents who select 'Yes' to a price option are directed to a higher bid, while those who select 'No' are omitted from the next question. This bidding process typically follow a banding, for example; Cost of PV: a) GBP 10,000, b) GBP 15,000, c) GBP 20,000, d) GBP 25,000 and percentage GHG reduction: a) $15 \%$, b) $20 \%$, c) $25 \%$, d) $30 \%$, etc. As a bidding process is followed with rates increased or decreased accordingly based on response, the ordering of questions 
becomes very important even in hypothetical studies. This presents a challenge in hand-delivered questionnaires as respondents do not necessarily complete questions sequentially. This means that there is a high likelihood of respondents seeing the next question before responding to earlier questions in the bidding process hence creating a response bias. To circumvent this and for more practical reasons, this paper followed a more straightforward bidding process similar to that of Hite et al. [40] and Nomura and Akai [24]. The respondents in this study were given a quote of GBP 16,000 for a $5 \mathrm{~kW}_{\mathrm{p}} \mathrm{PV}$.

The negotiation in this study involved the use of listed incentive discounts in the form of percentages rather than the previously illustrated cash bidding. The levels were $25 \%$, $30 \%, 40 \%, 50 \%$ and $60 \%$ with the 'other please specify' option. To arrive at the WTP amount, the option selected by the respondent was deducted from the total quoted PV cost. For example, if a respondent selected 50\%, it meant that they were WTP GBP 8,000 and so on and so forth. To gauge acceptance, the study had to assume the presence of government support incentives such that the households had to make part payment. A comparable approach was used by Kim et al. [25]. Table 2 details other biases that can arise from the use of questionnaires and bidding exercises and how they were controlled.

Table 2. Questionnaire design bias and controls

\begin{tabular}{cc}
\hline Questionnaire design bias & Control approach/devised solution \\
\hline Hypothetical bias & $\begin{array}{r}\text { The provision of part-payment option that helps to reduce total cost } \\
\text { payable while indicating collective effort. }\end{array}$ \\
Question ordering or sequence bias & $\begin{array}{r}\text { To elicit WTP in bidding exercises, the ordering of questions can affect } \\
\text { responses particularly for paper or hand-delivered questionnaires. This is } \\
\text { because respondents can view the bids before deciding on a price to } \\
\text { choose. To manage this problem, the questionnaire was split into } \\
\text { subsections such that links would not be easily spotted. }\end{array}$ \\
Interviewer or field assistant bias & $\begin{array}{c}\text { Self-completion questionnaire is less likely to influence respondent's } \\
\text { answers than face-to-face interviews as respondents are known to answer } \\
\text { 'Yes' when not meant, to satisfy researchers. }\end{array}$ \\
Title bias & $\begin{array}{c}\text { To the best of the researcher's knowledge, this bias is often } \\
\text { unacknowledged. Respondents can pick up clues from titles that may } \\
\text { influence responses, thereby affecting results. For this reason, the } \\
\text { questionnaire title was carefully selected to minimise such bias } \\
\text { impacting responses. }\end{array}$ \\
\hline
\end{tabular}

\section{RESULTS}

This section presents the results of the analysis that assesses the profile and characteristics of households willing to participate and pay for domestic solar PV.

\section{Descriptive statistics}

From the sample of 200 urban Lagos households, $75 \%$ were men and $25 \%$ women. Most of the respondents were between the ages of 31 and 44 years $(53.5 \%)$, 29\% were between 45 and 64 years, $14.5 \%$ were between 18 to 30 years, while $3 \%$ were 65 years and above. The changing family size of Nigerian households was also noted in the survey. Small households of 3 or less represented 55\% of the sample. Medium-large households with over 4 persons made up $45 \%$. Regarding education level, $85 \%$ had post-graduate education, $11 \%$ had undergraduate degree, those with secondary education represented $3 \%$ with the remainder being respondents with informal education.

In order to compare the sample on educational attainment with state and national representation, adult literacy rate data was used due to the lack of reliable statistics on national postgraduate qualifications. The national overall adult literacy of $71 \%$ with highest literacy rate was reported for urban areas in 2011. In particular, Lagos state was 
shown to have adult literacy of $87.7 \%$ [41] which is relatively close to the findings from this study. However, there was no significant gender difference in educational levels as Figure 2 shows.

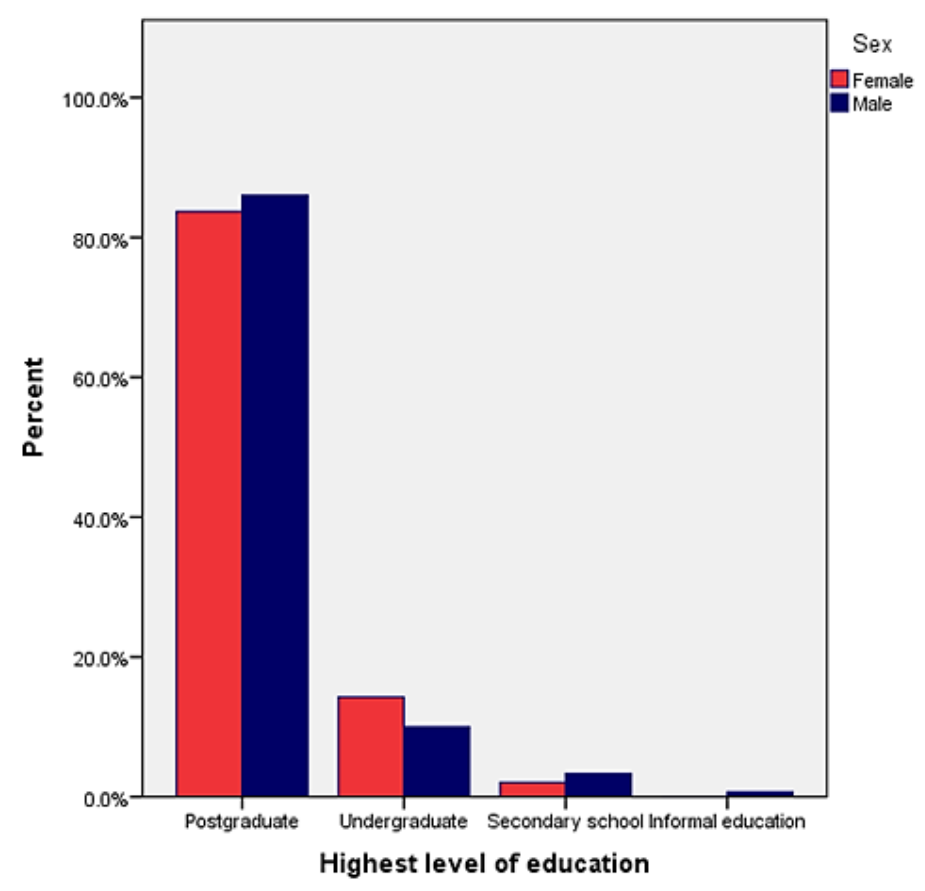

Figure 2. Educational level by gender

The income of the respondents was another variable of interest which could help explain the response to domestic PV for power generation. The average annual income band of the surveyed households was between GBP 12,000-20,000. About 5\% had monthly income of almost GBP 8,000. 10.7\% reported monthly earnings of between GBP 3,300-8,000. The proportion of households with income range of GBP 300-1,000 was $28.6 \%$. The monthly income for about $15.8 \%$ of the respondents was between GBP 1,300-3,300. People on the lowest income band (14.3\%) earned less than GBP 300 per month. Overall, for a developing country, about $31 \%$ of the respondents can be classed as medium to high income earners. It is important to note that most households in Nigeria have a secondary source of income. Reliable data could not be found on national income statistics hence representativeness on income cannot be ascertained. Nevertheless, given that many households generate income from a number of sources, it is likely that it can be higher or lower than found in this study.

Additionally, home ownership can impact WTP for microgeneration technologies. This was explored in this study. Almost $40 \%$ of the sampled population reported owning their own homes. Of this total, $25 \%$ were self-built and 10\% purchased outright from property developers and 1\% acquired through mortgage. A higher proportion (63\%) reported renting their homes. In relation to the representativeness of the sample, the $35 \%$ home ownership found in Lagos represents 53\% of national home ownership [41].

In terms of dwelling types, households who lived in duplexes and bungalows made up the second and third largest category in the property types, next only to households who lived in flats (53\%). Thus, all other things being equal, a majority of the dwelling types are suitable for mounting PV modules. However, it is important to note that for dwelling types such as flats there may be roof-space limitations due to roof-size and issues that can arise from multi-occupancy dwellings which could mean that PV installations in such dwellings be ground mounted taking into consideration the practical constraints and security risks this may present. 


\section{Household Willingness To Pay for a $5 \mathbf{k} W_{p}$ standalone Photovoltaic}

Overall WTP was high (49\%) in this study but higher (87\%) in the presence of government aid in the form of subsidies or incentives. The average amount households were willing to pay for a $5 \mathrm{~kW}_{\mathrm{p}}$ PV system was found to be GBP 8,000 as reflected in Figure 3. A high willingness to grid-tie when arrangements such as the feed-in-tariff and net metering becomes available was high at $72.5 \%$. Grid-connection would be central to increasing national generation capacity.

One way to validate mean WTP survey estimates is to compare it with non-market valuation studies or different but comparable studies [33, 38]. Average WTP for green power in Korea was about 3 times the average monthly electricity bill [25]. While a WTP of GBP 8,000 could be said to be high for a country like Nigeria, it need be remembered that it is for the purchase of a $5 \mathrm{~kW}_{\mathrm{p}} \mathrm{PV}$ module as against the mere participation and payment for green electricity supply that the above studies focused on. Hence, the amounts ranging 17-30 USD/month that households agreed to pay in Asia and 16.33 EUR/month they were WTP quarterly in Greece [42] was only reflective of centrally supplied green electricity. Also, WTP is expected to be high for households who are desperate to see their living conditions improve from regular and more reliable electricity that domestic solar PV can guarantee.

Cumulative responses to WTP for PV

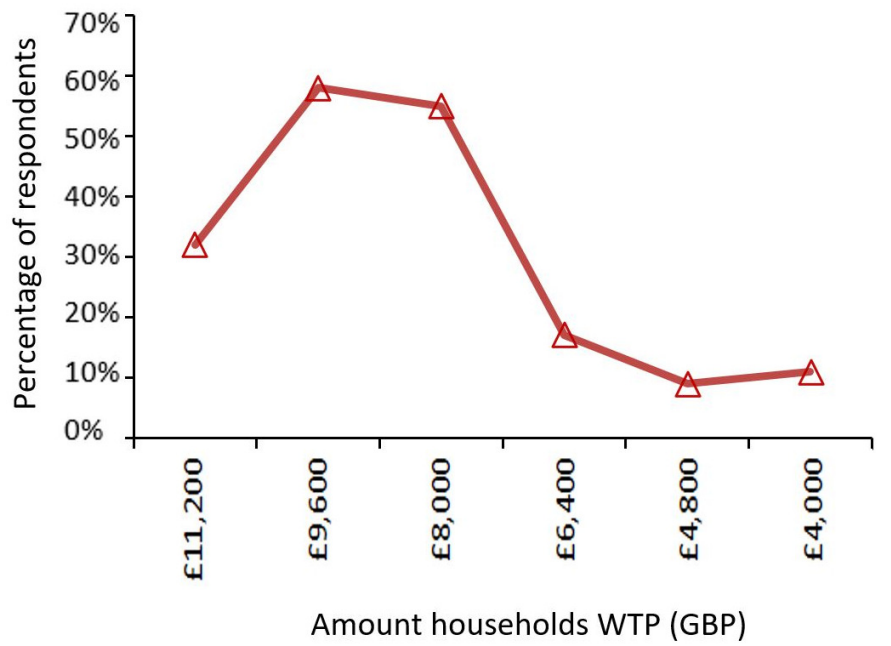

Figure 3. WTP for a $5 \mathrm{~kW}_{\mathrm{p}}$ domestic PV

\section{Sociodemographic factors linked to Photovoltaic valuation}

The correlation between gender and WTP was also examined. The purpose of the association in the line graph in Figure 4 was not to distinguish WTP between males and females. It was primarily to show the association with respect to age and amount the respondents were prepared to pay. Age and income are prime factors impacting household-level PV adoption. The results demonstrate a higher PV valuation as a function of increase in age. Individuals aged 18-30 were less WTP more than GBP 6,000. There was a noticeable rise in WTP from ages 31-44. However, the mean average WTP was GBP 8,000.

People under 30 have been previously found to show a lower acceptance and WTP for renewables. The low WTP for PV by those aged 18-30 years could be explained by the fact that many people that age are more likely to be in an early stage of their career with less funds for such investments. In general, middle-aged groups found PV more appealing and findings corroborate with previous researches. Sardianou and Genoudi [16] gave accounts of how the middle-aged and highly educated people showed higher 
WTP for MGTs. Leenheer et al. [26] found that people aged 60 and above revealed a lower intention to generate their own power from microgeneration.

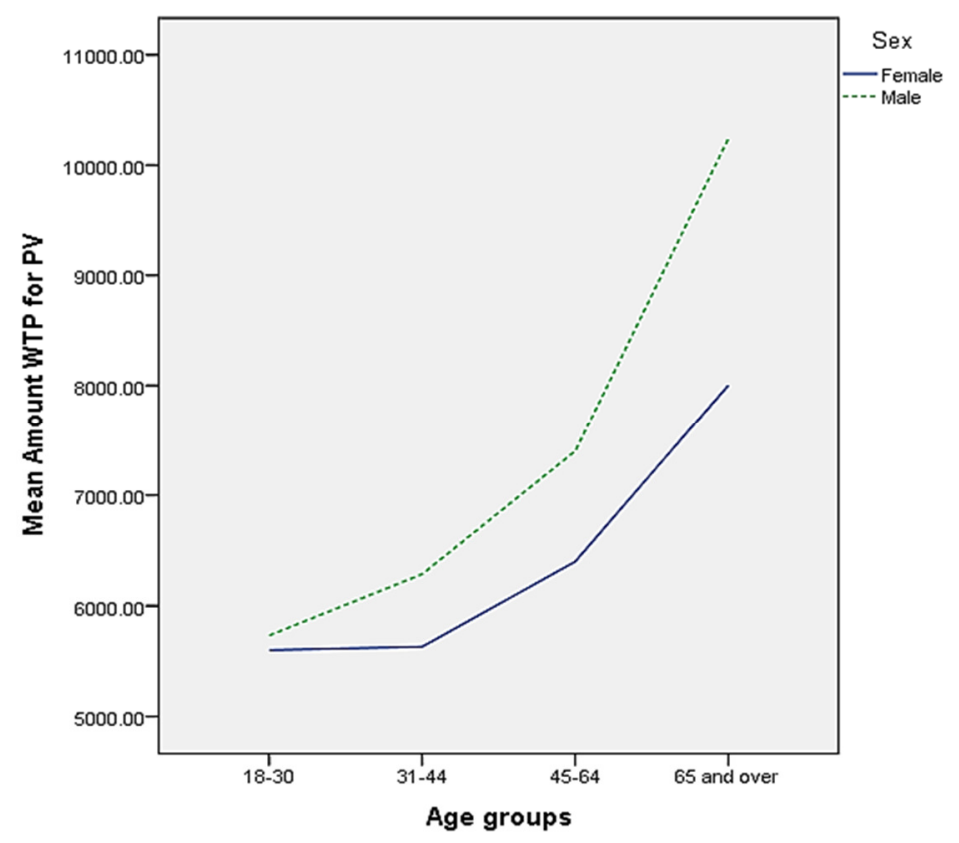

Figure 4. Mean WTP for PV by age and gender

Other sociodemographic factors such as income, education and home ownership revealed some relationships. Middle-higher income households showed a greater probability to pay for PV than low income groups. This was unsurprising since PV is still a premium technology. This finding is in agreement with Oliver et al. [15] who demonstrated that higher income earners were more likely to pay a premium for green electricity in South Africa. In Greece, Sardianou and Genoudi [16] reported the same for renewable self-generation. The correlation between education and adoption decisions have previously been confirmed [20].

Perhaps, this is to do with the fact that more educated people are more likely to spend the time to search for information and research a technology. However, income is not a significant determinant as previously documented [27]. This is because the WTP and participation decision is based on a number of interrelated socio-economic and environmental factors.

Regarding home ownership, a third of the surveyed respondents said they owned their homes but the correlation with participation were insignificant. It is easy to see why landlords may not worry about tenants installing PV on their buildings. It is an indication that the tenant is going to be staying in their property for a long duration ensuring a steady flow of rental income for the landlords. Also, in Nigeria, it is common for occupants in multi-occupant properties to contribute funds towards buying gasoline for generators so that everyone in the building can have electricity. Such level of cooperation amongst building occupants could help explain why housing tenure may not matter.

In Europe, Leenheer et al. [26] and Sardionou and Genoudi [16] demonstrated that home ownership was not a significant determinant of MGT adoption decision. However, in rural Kenya, home ownership was a significant factor for households' WTP for PV [38].

Building type can also impact PV uptake decision. In this study, next to households in flats, those in duplexes and bungalows showed more willingness to participate. This may have to do with the finding that they made the bulk of the total surveyed compared to individuals in other types of dwelling. However, building type can allow or limit uptake 
because the installation has to be made in such a way as to capture maximum solar radiation needed for proper function. Residents of some types of buildings found in Festac Town $^{\dagger}$, Lagos (Amuwo-Odofin LCA - under Badagry) would face similar hurdles. One solution for this group would be installing community PV.

While sociodemographic factors are not the best predictors of consumer response and WTP and participate in renewables uptake, it helps understand the underlying trends that can impact adoption in a household or from a citizen's perspective. Attitudinal, behavioural and economic factors would impact participation more because it directly links to the participation and investment decision.

\section{Incentive support and Willingness To Pay}

The role of incentives towards influencing PV diffusion is widely acknowledged. Results from this study also supports this theory, as when discounts in the form of Government incentives were offered, the households' acceptance of PV increased significantly to $87 \%$. When presented with forms of fiscal support for PV investment, a higher preference was shown for bank loans and import duty cuts compared to tax rebates. $41 \%$ showed interest in bank loans but the percentage of those who would not consider taking bank loans were much higher (59\%). About $31 \%$ preferred import duty cuts. The least preference was shown for tax cuts and VAT exemptions at $10 \%$. From the cumulative answers to the WTP elicitation question, the most preferred amount of subsidy was one that gave 50-60\% discount off total PV costs. However, any discount from $30 \%$ to $60 \%$ would yield meaningful patronage for PV.

\section{DISCUSSION AND CONCLUSIONS}

This paper has assessed urban Nigerian households' WTP for a hypothetical $5 \mathrm{~kW}_{\mathrm{p}}$ costing GBP 16,000. Compared to households in Asia and Africa, a very high WTP was recorded. Most households stated that they would pay if they received 50-60\% discount off the total cost. In the time following the data collection and analysis, PV costs have significantly reduced due to technological learning and economies of scale. Thus, the present average cost of a $5 \mathrm{~kW}_{\mathrm{p}}$ system is about half this amount. The very high valuation by Nigerian households is a utilitarian one pointing to the subsistence needs regular electricity helps to fill.

As a rule of thumb, the accepted budget for energy services is $10 \%$ of income [38]. In Nigeria, the average household spend on electricity was $15 \%$ of total monthly income with most households reported to spend about 25\% [43]. This also helps to explain the relatively high WTP a premium shown by the questionnaire respondents for improved grid electricity. Fewer respondents stated that they would be WTP if the Government provides as little as 5-10\% discounts for a GBP 16,000 PV system when they had the option to choose any discount level, $60 \%$ for instance. Utility from PV could have been a factor in the high valuation. It could as well be that some of the surveyed households may have been doubtful of the possibility of the Nigerian Government assisting with PV procurement hence increasing bids.

Nevertheless, caution should be applied. Results should not be interpreted to mean that most Nigerian households have suddenly become high income earners. Notwithstanding, the steady growth of the Nigerian economy and GDP for some years now at roughly $6 \%$ would mean that households earning power has improved. Although hypothetical bias can affect consumer response studies, the lesson to take is that there is huge interest in alternative and more sustainable electricity in Lagos, Nigeria. One of the limitations of this study is that it did not consider the economic loss to households of

${ }^{\dagger}$ FESTAC is a federal housing estate programme introduced in 1977 at the end of the world Festival of Arts and Culture (FESTAC) event in Lagos (Lagos State Government, Nigeria, 2014). 
using private generators and inverters. It would be worth researching this using a large sample, as well as researching the economic loss to Small and Medium-scale Enterprises (SMEs) and large business owners who have more funds and roof-space.

This study has shed light on the necessity for fiscal and non-monetary incentives to promote consumer PV uptake. Household participation would help ease the overburdened national electricity infrastructure. Findings from this study while particular to the locale would also find application in regions with similar power sector challenges.

\section{ACKNOWLEDGMENT}

This research received financial support from the Global Excellence and Stature (GES) fellowships.

\section{REFERENCES}

1. World Bank, The World Bank in Nigeria: Nigeria at a Glance, http://www.worldbank.org/en/country/nigeria, [Accessed: 10-November-2018]

2. United Nations (UN), Sustainable Development Goals 7: Clean Energy, 2018, https://www.un.org/sustainabledevelopment/energy/, [Accessed: 19-July-2018]

3. Ozoegwu, C. G., The Solar Energy Assessment Methods for Nigeria: The Current Status, the Future Directions and a Neural Time Series Method, Renewable and Sustainable Energy Reviews, Vol. 92, pp 146-159, https://doi.org/10.1016/j.rser.2018.04.050

4. Aliyu, A. S., Dada, J. O. and Adam, I. K., Current Status and Future Prospects of Renewable Energy in Nigeria, Renewable and Sustainable Energy Reviews, Vol. 48, pp 336-346, 2015, https://doi.org/10.1016/j.rser.2015.03.098

5. Sovacool, B. K., How Long Will it Take? Conceptualizing the Temporal Dynamics of Energy Transitions, Energy Research and Social Science, Vol. 13, pp 202-215, 2016, https://doi.org/10.1016/j.erss.2015.12.020

6. United Nations Environment Programme (UNEP), Renewable Energy: Renewables on the Rise, 2018, https://www.unenvironment.org/explore-topics/energy/what-wedo/renewable-energy, [Accessed: 29-July-2018]

7. Ozoegwu, C. G., Mgbemene, C. A. and Ozor, P. A., The Status of Solar Energy Integration and Policy in Nigeria, Renewable and Sustainable Energy Reviews, Vol. 70, pp 457-471, 2017, https://doi. org/10.1016/j.rser.2016.11.224

8. United Nations Treaty Collection (UNTC), Environment: Ratifications Status, https://treaties.un.org/Pages/ViewDetails.aspx?src=TREATY\&mtdsg_no=XXVII-7d\&chapter=27\&clang=_en, [Accessed: 26-June-2018]

9. Energy Sector Management Assistance Program (ESMAP), Assessing Low-carbon Development in Nigeria: An Analysis of Four Sectors, ESMAP Technical Paper, 2013, http://documents.worldbank.org/curated/en/2013/01/17977719/assessing-low -carbon-development-nigeria-analysis-four-sectors\#, [Accessed: 07-May-2014]

10. Financial Times (FT), Nigeria Power Rates to Rise up to 88\%, 2015, http://www.ft.com/cms/s/0/78b805ec-5586-11e1-9d95-00144feabdc0.html\# axzz3meyF6HX7, [Accessed: 20-September-2018]

11. Shaaban, M. and Petinrin, J. O., Renewable Energy Potentials in Nigeria: Meeting Rural Energy Needs, Renewable and Sustainable Energy Reviews, Vol. 29, pp 72-84, 2014, https:// doi.org/10.1016/j.rser.2013.08.078

12. Aliyu, A. S., Ramli, A. T. and Saleh, M. A., Nigeria Electricity Crisis: Power Generation Capacity Expansion and Environmental Ramifications, Energy, Vol. 61, pp 354-367, 2013, https:// doi.org/10.1016/j.energy.2013.09.011

13. Odukwe, A. O. and Mukhopadhyay, K., Appraisal of Photovoltaic Power Systems for Rural Development in Nigeria, Energy for Rural and Island Communities, pp 55-61, 1986, https:// doi.org/10.1016/B978-0-08-033423-3.50014-9 
14. Adhekpukoli, E., The Democratization of Electricity in Nigeria, Electricity Journal, Vol. 31, No. 2, pp 1-6, 2018, https://doi.org/ 10.1016/j.tej.2018.02.007

15. Oliver, H., Volschenk, J. and Smit, E., Residential Consumers in the Cape Peninsula's Willingness to Pay for Premium Priced Green Electricity, Energy Policy, Vol. 39, No. 2, pp 544-550, 2011, https:// doi.org/10.1016/j.enpol.2010.10.012

16. Sardianou, E. and Genoudi, P., Which Factors Affect the Willingness of Consumers to Adopt Renewable Energies?, Renewable Energy, Vol. 57, pp 1-4, 2013, https://doi.org/10.1016/j.renene.2013.01.031

17. Hast, A., Alimohammadisagvand, B. and Syri, S., Consumer Attitudes Towards Renewable Energy in China - The Case of Shanghai, Sustainable Cities and Society, Vol. 17, pp 69-79, 2015, https://doi.org/10.1016/j.scs.2015.04.003

18. Arega, T. and Tadesse, T., Household Willingness to Pay for Green Electricity in Urban and Peri-urban Tigray, Northern Ethiopia: Determinants and Welfare Effects, Energy Policy, Vol. 100, pp 292-300, 2017, https://doi.org/10.1016/j.enpol.2016.10.022

19. Noblet, C. L., Teisl, M. F., Evans, K., Anderson, M. W., McCoy, S. and Cervone, E., Public Preferences for Investments in Renewable Energy Production and Energy Efficiency, Energy Policy, Vol. 87, pp 177-186, 2015, https://doi.org/10.1016/j.enpol.2015.09.003

20. Kim, J., Park, S. Y. and Lee, J., Do People Really want Renewable Energy? Who wants Renewable Energy?: Discrete Choice Model of Reference-dependent Preference in South Korea, Energy Policy, Vol. 120, pp 761-770, 2018, https://doi.org/10.1016/j.enpol.2018.04.062

21. Guo, X., Liu, H., Mao, X., Jin, J., Chen, D. and Cheng, S., Willingness to Pay for Renewable Electricity: A Contingent Valuation Study in Beijing, China, Energy Policy, Vol. 68, pp 340-347, 2014, https://doi.org/10.1016/j.enpol.2013.11.032

22. Zorić, J. and Hrovatin, N., Household Willingness to Pay for Green Electricity in Slovenia, Energy Policy, Vol. 47, pp 180-187, 2012, https://doi.org/10.1016/j.enpol.2012.04.055

23. Sundt, S. and Rehdanz, K., Consumers' Willingness to Pay for Green Electricity: A Meta-analysis of the Literature, Energy Economics, Vol. 51, pp 1-8, 2015, https://doi.org/10.1016/j.eneco.2015.06.005

24. Nomura, N. and Akai, M., Willingness to Pay for Green Electricity in Japan as Estimated through Contingent Valuation Method, Applied Energy, Vol. 78, No. 4, pp 453-463, 2004, https:// doi.org/10.1016/j.apenergy.2003.10.001

25. Kim, J., Park, J., Kim, H. and Heo, E., Assessment of Korean Customers' Willingness to Pay with RPS, Renewable and Sustainable Energy Reviews, Vol. 16, No. 1, pp 695-703, 2012, https:// doi.org/10.1016/j.rser.2011.08.034

26. Leenheer, J., de Nooij, M. and Sheikh, O., Own Power: Motives of Having Electricity without the Energy Company, Energy Policy, Vol. 39, No. 9, pp 5621-5629, 2011, https:// doi.org/10.1016/j.enpol.2011.04.037

27. Balcombe, P., Rigby, D. and Azapagic, A., Motivations and Barriers Associated with Adopting Microgeneration Energy Technologies in the UK, Renewable and Sustainable Energy Reviews, Vol. 22, pp 655-666, 2013, https://doi.org/10.1016/j.rser.2013.02.012

28. Wiser, R. H., Using Contingent Valuation to Explore Willingness to Pay for Renewable Energy: A Comparison of Collective and Voluntary Payment Vehicles, Ecological Economics, Vol. 62, No. 3-4, pp 419-432, 2007, https://doi.org/10.1016/j.ecolecon.2006.07.003

29. World Bank, Sustainable Cities: What does Urban Mean?, 2015, http://blogs. worldbank.org/sustainablecities/what-does-urban-mean, [Accessed: 10-June-2017]

30. Lagos State Government, Nigeria, City Overview, 2014, http://www.lagosstate.gov.ng, [Accessed: 17-April-2014] 
31. Fagbenle, R. L., Oladiran, M. T. and Oyedemi, T. I., The Potential Generating Capacity of PV-Clad Residential and Commercial Buildings in Nigeria, no. 36762, pp 519-526, 2003, https://doi.org/10.1115/ISEC2003-44232

32. Colenbrander, S., Gouldson, A., Sudmant, A. H. and Papargyropoulou, E., The Economic Case for Low-carbon Development in Rapidly Growing Developing World Cities: A Case Study of Palembang, Indonesia, Energy Policy, Vol. 80, pp 24-35, 2015, https:// doi.org/10.1016/j.enpol.2015.01.020

33. Soon, J. J. and Ahmad, S. A., Willingly or Grudgingly? A Meta-analysis on the Willingness-to-pay for Renewable Energy Use, Renewable and Sustainable Energy Reviews, Vol. 44, pp 877-887, 2015, https://doi.org/10.1016/j.rser.2015.01.041

34. De Vaus, D., Surveys in Social Science Research ( $5^{\text {th }}$ ed.), Routledge Publishers, Abingdon, Oxon, UK, 2002.

35. Abdullah, S. and Mariel, P., Choice Experiment Study on the Willingness to Pay to Improve Electricity Services, Energy Policy, Vol. 38, No. 8, pp 4570-4581, 2010, https:// doi.org/10.1016/j.enpol.2010.04.012

36. Ida, T., Murakami, K. and Tanaka, M., A Stated Preference Analysis of Smart Meters, Photovoltaic Generation, and Electric Vehicles in Japan: Implications for Penetration and GHG Reduction, Energy Research and Social Science, Vol. 2, pp 75-89, 2014, https:// doi.org/10.1016/j.erss.2014.04.005

37. Louviere, J. J., Flynn, T. N. and Carson, R. T., Discrete Choice Experiments Are Not Conjoint Analysis, Journal of Choice Modelling, Vol. 3, No. 3, pp 57-72, 2010, https:// doi.org/10.1016/S1755-5345(13)70014-9

38. Abdullah, S. and Jeanty, P. W., Willingness to Pay for Renewable Energy: Evidence from a Contingent Valuation Survey in Kenya, Renewable and Sustainable Energy Reviews, Vol. 15, No. 6, pp 2974-2983, 2011, https://doi.org/10.1016/j.rser.2011.03.016

39. Claudy, M. C., Michelsen, C. and O'Driscoll, A., The Diffusion of Microgeneration Technologies - Assessing the Influence of Perceived Product Characteristics on Home Owners' Willingness to Pay, Energy Policy, Vol. 39, No. 3, pp 1459-1469, 2011, https:// doi.org/10.1016/j.enpol.2010.12.018

40. Hite, D., Duffy, P., Bransby, D. and Slaton, C., Consumer Willingness-to-pay for Biopower: Results from Focus Groups, Biomass and Bioenergy, Vol. 32, No. 1, pp 11-17, 2008, https:// doi.org/10.1016/j.biombioe.2007.07.002

41. Nigerian Bureau of Statistics, General Household Survey Panel 2010/2011, http://www.nigerianstat.gov.ng/library, [Accessed: 15-April-2012]

42. Zografakis, N., Sifaki, E., Pagalou, M., Nikitaki, G., Psarakis, V. and Tsagarakis, K. P., Assessment of Public Acceptance and Willingness to Pay for Renewable Energy Sources in Crete, Renewable and Sustainable Energy Reviews, Vol. 14, No. 3, pp 1088-1095, 2010, https:// doi.org/10.1016/j.rser.2009.11.009

43. Chidebell-Emordi, C., The African Electricity Deficit: Computing the Minimum Energy Poverty Line using Field Research in Urban Nigeria, Energy Research and Social Science, Vol. 5, pp 9-19, 2015, https://doi.org/10.1016/j.erss.2014.12.011 